\title{
EDITORIAL
}

\section{In This Issue: On-the-Ground Advances \& High-Level Influences}

\author{
Kurt C. Stange, $M D, P b D$, Editor \\ Ann Fam Med. 2017;15:102-104. https://doi.org/10.1370/afm.2061. \\ Conflict of interest: Kurt Stange bas been a member of the National Commission of Prevention Priorities since it began.
}

$\mathrm{T}$ This issue of Annals conveys new knowledge to support practice- and patient-level improvements in practice, and reveals policy-level factors that constrain or enhance on-the-ground work to improve health

\section{ON-THE-GROUND ADVANCES}

The sweet spot between the easy, usual way of measuring blood pressure and the hassle of 24 -hour monitoring is investigated by Bos and colleagues. ${ }^{1}$ They find that in-office automated blood pressure monitoring over 30 minutes results in a dramatic reduction in the number of patients who meet criteria for treatment intensification. In a related editorial, Green states that routine office blood pressures should no longer be used to diagnose or modify hypertension treatment. He calls for practice-based research and new approaches so that clinicians "get it right" for their patients. ${ }^{2}$

A prospective study of screening for diabetes compares point-of-care glycosylated hemoglobin testing with standard care, and finds a much higher rate of pre-diabetes diagnosis with systematic use of pointof-care glycosylated hemoglobin testing. The authors conclude that glycosylated hemoglobin "may be the most effective method to identify patients unknowingly living in hyperglycemia." ${ }^{13}$

Elmore et al experiment with offering patients in a large primary care safety net clinic the opportunity to type their visit agendas in the electronic visit note prior to seeing their clinician. ${ }^{4}$ Both patients and clinicians find that this improves communication, and most want to continue having patients type their agendas in the future. They conclude that "Enabling patients to type visit agendas may enhance care by engaging patients and giving clinicians an efficient way to prioritize patients' concerns."

Having both patients and physicians wash their hands is found by Doyle et al to be a promising approach to assuring high rates of use of this simple, important infection control practice. ${ }^{5}$
In a cluster randomized trial, LaPorte and colleagues find that a brief intervention by general practitioners working with young cannabis users has subtle effects in subgroups, but no overall effect on cannabis consumption. ${ }^{6}$

Parents' expectations regarding antibiotics for children with acute respiratory infections is evaluated by Hoffmann et al. They find that while most parents recognize potential harms from antibiotics, they overestimate their effect on symptom duration by 5 to 10 times. $^{7}$

The usefulness of antibiotics for children whose eczema appears infected is examined in a clinical trial by Francis et al. They find no added effect of topical or oral antibiotics over topical steroids and emollients. ${ }^{8}$

In a reflective personal essay, Ventres offers an internal blueprint for providing person-centered care. Seven "intentions of practice" help him attend to patients as complex human beings. ${ }^{9}$

Young et al approach patient-centeredness through a different lens. Their essay provides perspectives on the particular challenges of measuring quality in primary medical care. ${ }^{10}$

\section{HIGH-LEVEL INFLUENCES}

Care coordination across 11 countries is examined by Penm et al. ${ }^{11}$ They find that patients are less likely to experience poor care coordination if their primary care physician knows their history well, spends sufficient time with them, involves them in care, and explains things well. Among 11 high income countries, care coordination is poorest in the United States.

Rhodes and colleagues test the hypothesis that the Patient Protection and Affordable Care Act's expansion of access-now threatened - might overwhelm primary care by increasing access for millions of new patients. In 10 diverse states, by the measure of median wait times for new appointments, there was no evidence of being overwhelmed. ${ }^{12}$ Multiple other studies 
show that primary care is stretched dangerously thin. This study shows that despite being stretched, primary care has the ability to adapt to meet demands when policy changes bring additional opportunities for service.

In a study of the long-term "imprint" of training, Phillips and colleagues find that the spending pattern of physicians training in high cost vs low cost Hospital Service Areas persists long after training. ${ }^{13}$

An article by authors from the Patient-Centered Outcomes Research Institute (PCORI) shares an Engagement Rubric developed from multiple sources. Building on decades of prior work in participatory research by others, the PCORI Engagement Rubric provides a framework for involving patients and other stakeholders in all phases of research. ${ }^{14}$

We welcome your reflections at http://www.Ann FamMed.org.

\section{GRATITUDE AND TRANSITIONS}

The Annals' Editorial Advisory Board provides crucial strategic advice about the journal's direction, connections, and the conversations in which we participate. They also provide critical connections to diverse people and ideas served by Annals. We would like to thank the following outgoing Board members for their years of guidance and insights:

- Richard Antonelli, MD

- Ed Bope, MD

- Carolyn Clancy, MD

- Nicole Gentile, MD

- Ann Louise Kinmonth, MD

- Steve Reid, MD

- Moira Stewart, PhD

- Richard "Mort" Wasserman, MD

- Jack Westfall, MD

We are delighted to welcome four new members to the Board:

- Sarah Burbank, BS, Rush Medical College (student member)

- Alexander Fiks, MD, MSCE, Children's Hospital of Philadelphia and Pediatric Research in Office Settings

- Robert McNellis, MPH, PA, Agency for Health Care Research and Quality

- Sally Okun, RN, MMHS, PatientsLikeMe Over the past year, the Annals team has benefitted greatly from the service of 2 Editorial Fellows who, in addition to learning about the processes of editing and publishing a journal and undertaking special projects, have functioned as editors. We are grateful for their outstanding work with us:

- Alan Adelman, MD, MS

- Michael Johansen, MD

Finally, we are happy to welcome Ahmed Rashid, $\mathrm{MBChB}, \mathrm{MSc}$, MRCGP as the new Annals Editorial Fellow. Ahmed currently is a clinical teaching fellow at the University College of London Medical School and brings clinical, teaching, research, and social media expertise to his work with us.

\section{References}

1. Bos MJ, Buis S. Thirty-minute office blood pressure monitoring in primary care. Ann Fam Med. 2017;15(2):120-123.

2. Green LA. It is time to change how we measure blood pressures in the office. Ann Fam Med. 2017;15(2):105-106.

3. Whitley HP, Hanson C, Parton JM. Systematic diabetes screening using point-of-care $A_{1 c}$ testing facilitates identification of prediabetes. Ann Fam Med. 2017;15(2):162-164.

4. Anderson MO, Jackson SL, Oster NV, et al. Patients typing their own visit agendas into an electronic medical record: pilot in a safety-net clinic. Ann Fam Med. 2017;15(2):158-161.

5. Doyle GA, Xiang J, Zaman $\mathrm{H}$, et al. Patient attitudes and participation in hand co-washing in an outpatient clinic before and after a prompt. Ann Fam Med. 2017;15(2):155-157.

6. Laporte C, Vaillant-Roussel H, Pereira B, et al. Cannabis and young users - a brief intervention to reduce their consumption (CANABIC): a cluster randomized controlled trial in primary care. Ann Fam Med. 2017;15(2):131-139.

7. Coxeter PD, Del Mar C, Hoffmann TC. Parents' expectations and experiences of antibiotics for acute respiratory infections in primary care. Ann Fam Med. 2017;15(2):149-154. 
8. Francis NA, Ridd MJ, Thomas-Jones E, et al. Oral and topical antibiotics for clinically infected eczema in children: a pragmatic randomized controlled trial in ambulatory care. Ann Fam Med. 2017;15(2):124-130.

9. Ventres WB. Looking within: intentions of practice for personcentered care. Ann Fam Med. 2017;15:171-174.

10. Young RA, Roberts RG, Holden RJ. The challenges of measuring, improving, and reporting quality in primary care. Ann Fam Med. 2017;15(2):175-182.

11. Penm J, Mackinnon NJ, Strakowski SM, Ying J, Doty MM. Minding the gap: factors associated with primary care coordination of adults in 11 countries. Ann Fam Med. 2017;15(2):113-119.

12. Rhodes KV, Basseyn S, Friedman AB, Kenney GM, Wissoker D, Polsky D. Access to primary care appointments following 2014 insurance expansions. Ann Fam Med. 2017;15(2):107-112.

13. Phillips RL, Petterson SM, Bazemore AW, Wingrove P, Puffer JC. The effects of training institution practice costs, quality, and other characteristics on future practice. Ann Fam Med. 2017;15(2):140-148.

14. Sheridan S, Schrandt S, Forsythe L, Hilliard TS, Paez KA. The PCORI Engagement Rubric: promising practices for partnering in research. Ann Fam Med. 2017;15(2):165-170.

\section{CORRECTION}

Ann Fam Med 2017;15:104. https://doi.org/10.1370/afm.2047.

In Maciosek MV, LaFrance A, Dehmer SP, McGree D, Flottemesch TJ, Xu Z, Solberg LI. Updated priorities among effective clinical preventive services. Ann Fam Med. 2017;15(1):14-22, there is a typo in Table 1 . In the 2nd column, for the score 4 row, the range should be 0 to 33,500 , not 0 to 3,500 . We regret the error.

\section{Get the Annals of Family Medicine by E-mail}

Make sure you see every new issue

while it's fresh; have the table of

contents sent to you by e-mail for

easy access to articles of interest.

Don't miss important research.

Request the e-mail table of contents at

http://www2.highroadsolution.com/

aafp_annals_preference_center/search.aspx
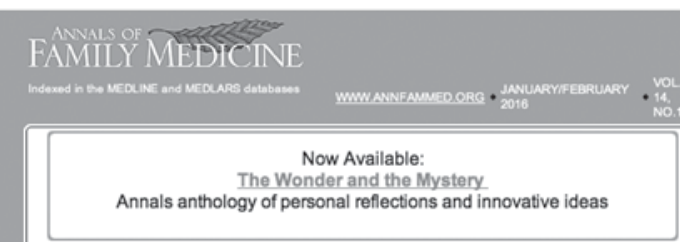

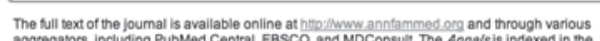
aggregators, including PubMed Central, EBSCO, and MDConsult The A Anatsis is indexed in the
MEDLLINE and MEDLARS, Solence Citation index Expanded, Current Contents Clinical Medidine, MEOLINE and MEOLARS, SClenoe Citation ind
PSyciNFO, EMBASE, and CINHAL databases.

EDITORIALS

Kurt C. Stange

Kunt C. Stango

Achieving PCMH Stans May Not Be Meaningtul for Small Practices
Kelley K Glancey; James a Konedy

Kelley K Glancer; James Q Konnedy

The Paradox of Size: How Small, Independent Practices Can Thrive in Valve-Based Carte

DRIGINAL RESEARCH

Solo and Small Practices: A Vital, Diverse Part of Primary Care

Winston R. Liaw; Anuradhe Jetty; Stephen Petterson: Lars E. Poterson: Andrw W. Bazemare Family physicians in solo and small practices outnumber those in larger practices.

Large Indegendent Primay Care Medical Groups

Lawrence P. Casalino; Melinda A. Chen; C. Todd Staub; Matthew J. Press; Jayme L Mendelsohn; Jahn T. Lynch; Yesenia Miranda

Large physician-owned groups have the potential to make primary care attractive to physicians

Primary Care Physiclan Panel Size and Quality of Care: A Poovilation-Based Study in Ontario.

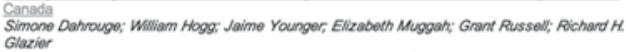
In Ontario, larger patient panel sizes do not decrease quality of care, but cancer screening rates In Ontario, larger
are slightly lower.

Willingness to Exchange Health Information via Mobile Devices: Findings From a Kathina J. Serrano; Mand Yu, WWiam T. Rivey; Vaishall Patel; Penelope Hughes; Kathyn Marchesin', Audie A. Atienzs 


\section{EDITORIAL}

\section{It is Time to Change How We Measure Blood Pressures in the Office}

Lee A. Green, MD, MPH

Family Medicine, University of Alberta, Edmonton, Alberta, Canada
$\mathrm{F}$ or a typical patient in my practice with Stage I hypertension and 1 or more other cardiovascular risk factors, the number needed to treat (NNT) for 5 years to prevent a death, acute coronary event, stroke, heart failure, or renal failure is only 11 , and patients at higher risk (especially those with known coronary or renal disease) benefit even more. ${ }^{1,2}$ With such a large benefit for outcomes that matter so much to patients, and a condition so many patients have, treating hypertension properly is clearly one of the most important things we do in family medicine.

We have to measure blood pressure accurately to treat it properly. In practice that's always been a problem. Our evidence base for hypertension treatment is clinical trials that used standardized office blood pressure (SOBP) measurement. SOBP requires the patient be seated at rest for 5 minutes, with feet on the floor, back supported, and arm supported at mid-chest height. When giving continuing medical education talks, I find that describing SOBP and asking the audience, "Is it always done that way in your practice?" reliably produces laughter.

Worse, even when done properly, SOBP is neither especially consistent and repeatable ${ }^{3}$ nor the best predictor of outcomes. ${ }^{4}$ White-coat hypertension is common, and can mislead us into overtreating blood pressure.

Is that bad? Some believe that white-coat hypertension, although less dangerous than sustained hypertension, still leads to more adverse outcomes than normotension and thus does merit treatment. ${ }^{5,6}$

Conflicts of interest: author reports none.

\section{CORRESPONDING AUTHOR}

Lee A. Green, MD, MPH

8440112 St, NW

Family Medicine

University of Alberta

Edmonton, Alberta, Canada T6G 2R7

lagreen@ualberta.ca
Franklin et $\mathrm{al}^{7}$, however, recently published a more careful analysis demonstrating that when age and risk are properly matched, white-coat hypertension patients do not have worse outcomes than similar normotensive patients. Overdiagnosing hypertension can have costly financial and social consequences for patients, and overtreating imposes annoying burden (and cost) even on those who have hypertension. Nor can we assume overtreatment is medically harmless. Overtreating is essentially unknowingly treating to a more aggressive than standard level of blood pressure reduction, and the SPRINT trial ${ }^{8}$ demonstrated a substantial rate of serious adverse events from doing so. Those adverse events may be worth risking for the high-risk patients who meet the inclusion criteria for SPRINT, but imposing the harms of overtreatment on low-risk patients-or those who do not even have hypertension at all-is unjustifiable.

So how do we avoid overtreatment? The gold standard is 24-hour ambulatory blood pressure monitoring. While it certainly has a place, however, it is somewhat costly and cumbersome even for initial diagnosis. For routine monitoring it would be quite impractical. Home monitoring can be very useful for those patients motivated to do it reliably, but what about everyone else?

Fortunately, over the last 15 years or so a significant body of evidence has emerged in primary care practices on automated office blood pressures collected with patients sitting undisturbed 6 times over 5 to 10 minutes (AOBP) $)^{4,9,10}$ or every 5 minutes for 30 minutes (OBP30). ${ }^{3,11} \mathrm{AOBP}$ and $\mathrm{OBP} 30$ are superior to routine office blood pressure measurement and to SOBP, closely approximating (for daytime pressures, at least) continuous ambulatory monitoring. Both methods could allow us to avoid overdiagnosis and overtreatment. Do they, in practice?

In this issue, Bos \& Buis $^{12}$ take the next necessary step. They provide evidence that treatment decisions change for a significant number of patients when OBP30 is used, compared to routine office blood pressures. At 
this point the evidence seems clear: routine office blood pressures, and even SOBP, should no longer be used to diagnose hypertension nor to adjust treatment.

So what are the implications for practice change? Aside from the obvious equipment needs, we will need to change our thinking on diagnosis and treatment thresholds, choose a method, and implement our choice properly. A well-done practice-based research network study comparing AOBP and OBP30 is an important first step. Since SPRINT used an abbreviated AOBP, with just 3 measurements, adding that to the comparison would be valuable. We need to know whether AOBP or abbreviated AOBP, done in a few minutes, are just as good as a 30-minute protocol, or if there is a convenience/accuracy tradeoff we need to consider.

We also will need to rethink our thresholds. The threshold for Stage 1 hypertension of 140/90 is drawn from studies using SOBP. Home and continuous ambulatory blood pressures run lower, and as AOBP and OBP30 closely approximate daytime ambulatory pressures, using 140/90 would result in underdiagnosis and undertreatment. Myers et $\mathrm{al}^{13}$ have provided observational evidence based on patient-oriented outcomes for $135 / 85$, at least for older adults. Replication and extension to younger populations, and to patients with higher risk profiles, is needed. Ideally the evidence for practice should come from practice-again suggesting that practice-based research networks are the best laboratories.

Changing how we do things in our offices may be a challenge too. Both AOBP (whether standard or abbreviated) and OBP30 require setting a patient up and then leaving them undisturbed while the measurements are taken. If we are to avoid overdiagnosing and overtreating due to the white-coat effect, we "white coats" need to stay out of the room! (Taking off the coat won't fool anyone's sympathetic nervous system, either.) For some practices that will be easy, but for some of us it will mean at least changing our routines, and sometimes even rearranging our offices. Getting it right will be a good use for our teams' quality improvement skills. Because hypertension treatment matters so much to so many, we owe it to our patients to get it right.
To read or post commentaries in response to this article, see it online at http://www.annfammed.org/content/15/2/105.

Key words: hypertension; blood pressure determination; white coat hypertension; practice patterns, physicians'

\section{References}

1. Chobanian AV, Bakris GL, Black HR, et al; National Heart, Lung, and Blood Institute Joint National Committee on Prevention, Detection, Evaluation, and Treatment of High Blood Pressure; National High Blood Pressure Education Program Coordinating Committee. The Seventh Report of the Joint National Committee on Prevention, Detection, Evaluation, and Treatment of High Blood Pressure: the JNC 7 report. JAMA. 2003;289(19):2560-2572.

2. Ogden LG, He J, Lydick E, Whelton PK. Long-term absolute benefit of lowering blood pressure in hypertensive patients according to the JNC VI risk stratification. Hypertension. 2000;35(2):539-543.

3. Scherpbier-de Haan N, van der Wel M, Schoenmakers G, et al. Thirty-minute compared to standardised office blood pressure measurement in general practice. Br J Gen Pract. 2011;61(590):e590-e597.

4. Beckett L, Godwin M. The BpTRU automatic blood pressure monitor compared to 24 hour ambulatory blood pressure monitoring in the assessment of blood pressure in patients with hypertension. BMC Cardiovasc Disord. 2005;5(1):18.

5. Briasoulis A, Androulakis E, Palla M, Papageorgiou N, Tousoulis D. White-coat hypertension and cardiovascular events: a meta-analysis. J Hypertens. 2016;34(4):593-599.

6. Mancia G. Clinical significance of white-coat hypertension. J Hypertens. 2016;34(4):623-626.

7. Franklin SS, Thijs L, Asayama K, et al; IDACO Investigators. The cardiovascular risk of white-coat hypertension. J Am Coll Cardiol. 2016;68(19):2033-2043.

8. Wright JT Jr, Williamson JD, Whelton PK, et al; SPRINT Research Group. A randomized trial of intensive versus standard bloodpressure control. N Engl J Med. 2015;373(22):2103-2116.

9. Myers MG, Kaczorowski J, Dawes M, Godwin M. Automated office blood pressure measurement in primary care. Can Fam Physician. 2014;60(2):127-132.

10. Myers MG. A short history of automated office blood pressure - 15 years to SPRINT. J Clin Hypertens (Greenwich). 2016;18(8):721-724.

11. van der Wel MC, Buunk IE, van Weel C, Thien TABM, Bakx JC. A novel approach to office blood pressure measurement: 30-minute office blood pressure vs daytime ambulatory blood pressure. Ann Fam Med. 2011;9(2):128-135.

12. Bos MJ, Buis S. Thirty-minute office blood pressure monitoring in primary health care. Ann Fam Med. 2017;15(2):120-123.

13. Myers MG, Kaczorowski J, Paterson JM, Dolovich L, Tu K. Thresholds for diagnosing hypertension based on automated office blood pressure measurements and cardiovascular risk. Hypertension. 2015;66(3):489-495. 